\title{
Where do we go now?
}

\author{
James S. Tweddell, MD
}

\author{
From The Heart Institute, Cincinnati Children's Hospital Medical Center, Cincinnati, Ohio. \\ Disclosures: Author has nothing to disclose with regard to commercial support. \\ Received for publication July 2, 2015; accepted for publication July 2, 2015; available ahead of print July 28, \\ 2015. \\ Address for reprints: James S. Tweddell, MD, The Heart Institute, Cincinnati Children's Hospital Medical Center, \\ 3333 Burnet Ave. MLC 2013, Cincinnati, OH 45229-3026 (E-mail: James.Tweddell@ CCHMC.org). \\ J Thorac Cardiovasc Surg 2015;150:1453-4 \\ $0022-5223 / \$ 36.00$ \\ Copyright (c) 2015 by The American Association for Thoracic Surgery \\ http://dx.doi.org/10.1016/j.jtcvs.2015.07.009
}

Shunji Sano reintroduced the right ventricular to pulmonary artery conduit modification of the Norwood procedure (NW-RVPA) in 2003. ${ }^{1}$ Many programs adopted this modification because it appeared to offer a less challenging early postoperative course than that of the Norwood procedure with a Blalock-Taussig shunt. The benefit of the NW-RVPA relative to the Norwood procedure with a Blalock-Taussig shunt in the early outcomes was confirmed by the Single Ventricle Reconstruction (SVR) trial, which demonstrated better survival at 1 year among those patients randomly assigned to undergo the NW-RVPA. ${ }^{2}$ The disadvantage of the NW-RVPA is the necessity for a ventriculotomy, with its attendant potential impact on late right ventricular function. ${ }^{3}$ A follow-up from the SVR trial showed that whatever survival advantage the NW-RVPA demonstrated in the first year is lost by the third year. ${ }^{4}$ There was an early survival benefit to the NW-RVPA, but there was a price to be paid in decreased late survival, presumably related to the deleterious effects of the ventriculotomy.

Now, in this issue of the Journal, Wilder and colleagues ${ }^{5}$ from the Congenital Heart Surgeons Society (CHSS) report on the outcome of a prospective observational study using propensity matching to compare 169 patients undergoing a Norwood procedure with a Blalock-Taussig shunt with 169 patients undergoing a NW-RVPA. Although the methodologies of the 2 studies are different, there are important similarities between the SVR trial and the CHSS study. The median durations of follow-up were similar, at 5.0 years for the SVR trial and 4.8 years for the CHSS study, as were the transplantfree survivals. A potentially important difference between the studies lies in the dates of enrollment, which were 2005 to 2008 for the SVR trial and 2005 to 2014 for the CHSS study, so that the CHSS study includes some more recent experience. Wilder and colleagues ${ }^{5}$ found improved survival and less potential for right ventricular dysfunction and tricuspid regurgitation among those undergoing the NW-RVPA. In contrast to the SVR trial, the current CHSS study shows a sustained survival benefit associated with the NW-RVPA. The CHSS study is not a randomized, controlled trial, and the shortcomings of the prospective observational

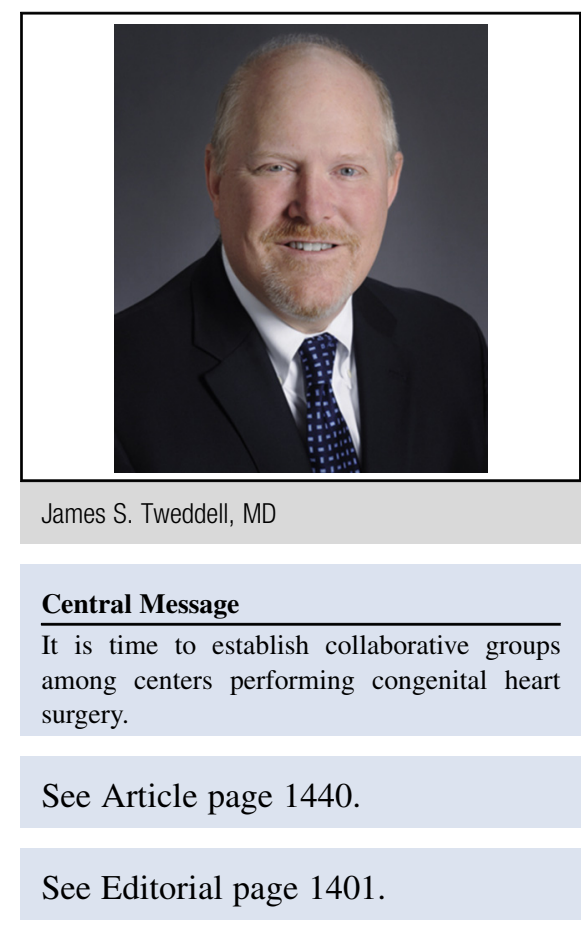

study are well known. The authors acknowledge that center and era effect were not accounted for in their propensity matching; nonetheless, the results suggest that late accelerated attrition or "catch-up mortality" is not evident among the NW-RVPA group. Furthermore, we do not see a decrease in function or worse tricuspid regurgitation among the patients in the NW-RVPA group. How do we account for these findings? Could this be evidence of a learning curve among the institutions and surgeons? Remember that the SVR trial was initiated shortly after the reintroduction of the NWRVPA, and many institutions had only recently taken up the new procedure, whereas the CHSS study extends into 2014. Perhaps there have been important modifications in the ventriculotomy and distal anastomosis that have impacted right ventricular function and pulmonary artery anatomy in ways that are difficult to measure.

Despite the intriguing differences in outcome between the 2 studies, the overall picture painted by both the SVR trial and the CHSS study is that of poor long-term survival. At 6 years, only about $60 \%$ of patients remain alive, notwithstanding the fact that the outcomes of Norwood palliation are frequently used as a benchmark for program performance and that a great deal of resources are expended on this population. It is time to have the courage to confess that we need a more overarching quality improvement strategy. 
Transparency and sharing of results will identify areas of underperformance that will benefit from collaboration in areas of technique, care and resource allocation. This approach has been successful in adult cardiac surgery, where collaboration between sites with higher and lower performances resulted in reduced variation in care, improved outcomes, and lower cost. ${ }^{6,7}$ Similar to the adult experience, the SVR trial identified important practice variation that did not correlate with outcome, and this finding suggests that there would be similar benefit to collaborative learning. ${ }^{8}$ An additional strategy to improve outcome would be to consolidate programs performing complex neonatal surgery such as the Norwood procedure to eliminate low-volume programs and thus take advantage of the volume-outcome relationship. The outcome of the Norwood procedure is dependent on both program and surgeon volume. ${ }^{9,10}$ The development of centers of excellence would concentrate resources on complex patient populations and permit a broader scope of investigation to include improved medical therapy, regenerative therapy, mechanical support, and transplantation for the failing single ventricle. None of these can be well studied in small, isolated programs. We also need to look at outcomes in addition to survival, such as functional status, quality of life, and neurodevelopmental outcome. The contribution of Wilder and colleagues ${ }^{5}$ is important and identifies a potentially durable benefit to the NW-RVPA, but perhaps now is the time to focus on strategies between programs rather than solely within programs.

\section{References}

1. Sano S, Ishino K, Kawada M, Arai S, Kasahara S, Asai T, et al. Right ventricle-pulmonary artery shunt in first-stage palliation of hypoplastic left heart syndrome. J Thorac Cardiovasc Surg. 2003;126:504-9; discussion 509-10.

2. Ohye RG, Sleeper LA, Mahony L, Newburger JW, Pearson GD, Lu M, et al; Pediatric Heart Network Investigators. Comparison of shunt types in the Norwood procedure for single-ventricle lesions. N Engl J Med. 2010;362: 1980-92.

3. Frommelt PC, Gerstenberger E, Cnota JF, Cohen MS, Gorentz J, Hill KD, et al; Pediatric Heart Network Investigators. Impact of initial shunt type on cardiac size and function in children with single right ventricle anomalies before the Fontan procedure: the single ventricle reconstruction extension trial. J Am Coll Cardiol. 2014;64:2026-35.

4. Newburger JW, Sleeper LA, Frommelt PC, Pearson GD, Mahle WT, Chen S, et al; Pediatric Heart Network Investigators. Transplantation-free survival and interventions at 3 years in the single ventricle reconstruction trial. Circulation. 2014; 129:2013-20.

5. Wilder TJ, McCrindle BW, Phillips AB, Blackstone EH, Rajeswaran J, Williams WG, et al; from the Congenital Heart Surgeons' Society. Survival and right ventricular performance for matched children after stage-1 Norwood: modified Blalock-Taussig shunt versus the right ventricular to pulmonary artery conduit. J Thorac Cardiovasc Surg. 2015;150:1440-54.e1-8.

6. Malenka DJ, O'Connor GT. The Northern New England Cardiovascular Disease Study Group: a regional collaborative effort for continuous quality improvement in cardiovascular disease. Jt Comm J Qual Improv. 1998;24: 594-600.

7. Birkmeyer NJ, Share D, Campbell DA Jr, Prager RL, Moscucci M, Birkmeyer JD. Partnering with payers to improve surgical quality: the Michigan plan. Surgery. 2005;138:815-20.

8. Pasquali SK, Ohye RG, Lu M, Kaltman J, Caldarone CA, Pizarro C, et al; Pediatric Heart Network Investigators. Variation in perioperative care across centers for infants undergoing the Norwood procedure. J Thorac Cardiovasc Surg. 2012; 144:915-21.

9. Hornik CP, He X, Jacobs JP, Li JS, Jaquiss RD, Jacobs ML, et al. Relative impact of surgeon and center volume on early mortality after the Norwood operation. Ann Thorac Surg. 2012;93:1992-7.

10. Pieper D, Mathes T, Asfour B. A systematic review of the impact of volume of surgery and specialization in Norwood procedure. BMC Pediatr. 2014;14:198. 